\title{
Melissus as an Analytic Metaphysicist
}

\author{
Vincenzo Fano $^{1}$ (D) Pierluigi Graziani ${ }^{1}$ - Flavia Marcacci ${ }^{2}$. \\ Mirko Tagliaferri ${ }^{1}$
}

Received: 29 April 2020 / Accepted: 27 July 2020/Published online: 13 August 2020

(C) The Author(s) 2020

\begin{abstract}
The aim of this paper is to reconstruct the logical structure of Melissus philosophy, building on Laks Most's translation and Barnes' seminal work on the Samian. This will allow us to shed some light on the subtle argumentations of Melissus. On top of that, we frame Melissus' metaphysics employing modern logical instruments. On one side, this reformulation makes clear a few assumptions hidden in the deductions made by the Samian; on the other side, our paper shows that contemporary analytic metaphysics has forerunners dating back 2500 years.
\end{abstract}

Keywords Ancient metaphysics · Monism · Immutability · Infinity of being

\section{Introduction}

In the last forty years analytic metaphysics became more and more important in the general philosophical debate. Scholars like Chisholm (1976), Lewis (1986) and Simons (1987) - to mention only few-proposed logical analyses of ontological concepts which are now crucial to the endeavour of metaphysics. Even if one

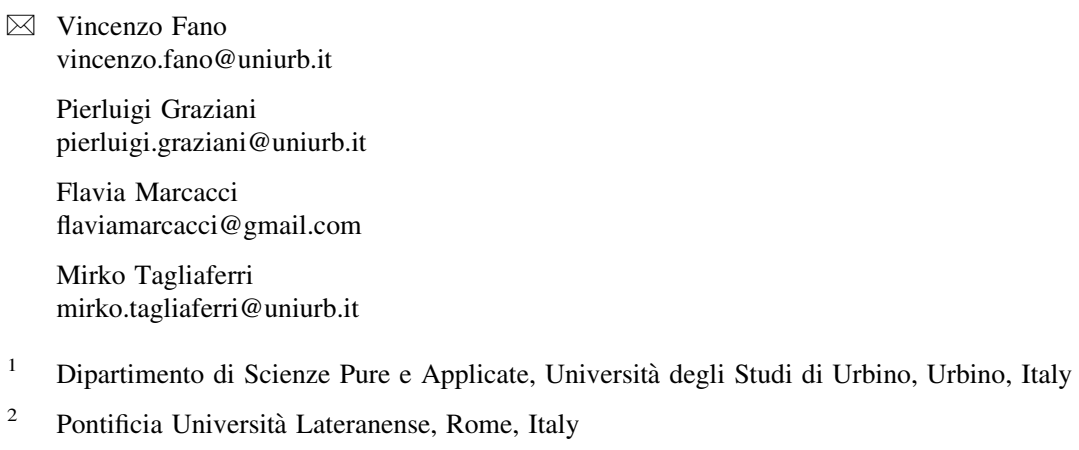


accepts Ladyman and Ross (2007) criticism and subsequent empirical turn, logicoontological instruments are essential to do serious metaphysics. ${ }^{1}$

The main point of the present paper is that, although formal methods in philosophy became common in the twentieth century, in Eleatic philosophy abstract logical reasonings in metaphysics were already employed, reaching a level comparable to the contemporary one. To show this, we discuss Melissus' fragments using simple logical methods. ${ }^{2}$

In this paper the aim is to prove how insightful and profound are ancient forms of monism. Specifically, the focus will be placed on Melissus' monism. ${ }^{3}$ We pay attention to this topic in view of the fact that monism - the thesis which holds that there exists only one (non-abstract ${ }^{4}$ ) object-has gained new life in the philosophical literature. Moreover, a form of existence monism has been recently ascribed to the Samian (Schaffer 2016) and, thus, Melissus can be seen as a fulcrum of contemporary debates on the topic of monism.

According to those new analyses, there are various typologies of monism. Those typologies can be classified according to their target-where the differentiating criterion is which kind of entity one states that there is (assuming that there is only one of it)—or according to their unit-where the differentiating criterion is how to count such entities (and, therefore, how to establish that there is only one entity). For instance, one can hold that there exists only one maximally general type of abstract objects, where the targets are abstract objects and the unit is the maximum genus. It has been particularly emphasized (ibid.) that the two historically most relevant typologies of monism are: existence monism and priority monism. The former affirms that only one concrete token object exists, i.e., the world. The latter affirms that different concrete objects exist in the world, but, the characteristics of all those concrete objects are determined by the properties of a unique basic concrete object. ${ }^{5}$

In our approach, Melissean monism will be described and interpreted using contemporary logical techniques. We should point out that we will not propose a new philological analysis of Melissus, but we will concentrate on the way his thoughts can be interpreted through the lenses of contemporary formal languages. The result will prove to be a particularly interesting form of monism, which can

\footnotetext{
1 Keeping fixed the point that it is not possible to do fully a priori metaphysics.

2 Melissus' rehabilitation as a rigorous thinker is due above all to Barnes (1982, p. 180ff.). Before appeared the wonderful Vitali's (1973) book. See also the just published Harriman (2019). For a very dismissive presentation of Melissus, see, for instance, Hussey (1997, pp. 148-149).

${ }^{3}$ We are aware that Simplicius - the main textual source for Melissus-attempts to see in Melissus a form of dualism in agreement with his Neoplatonist philosophy, see Loenen (1951, p. 129), but we won't take into consideration his interpretation, but only his textual evidence.

${ }^{4}$ I.e. an object which was not submitted to any mental activity of generalization and/or composition.

5 Therefore, in this last typology of monism, the targets are concrete objects and the unit is a basic and ontologically fundamental object, where "fundamental" should be interpreted as ontological dependence. Thus, priority monist claims that, even though many smaller objects exist (World parts), there is only a unique object which has fundamental properties, i.e., the World. Above those typologies of monism, it is possible to distinguish a further type of monism, i.e., substance monism. Substance monism's targets are, again, concrete objects, but the unit is the genus. Thus, according to this view, objects refer all to the same genus.
} 
provide insights to current researchers in metaphysics. In particular, we will read Melissus through Simplicius' transmitted text, without attempting a more veridical interpretation. ${ }^{6}$

Melissus' monism is a historically important thesis. Last among the Eleatic philosophers, Melissus is influenced by the results of Parmenides and Zeno. He takes the moves from Parmenides' ontology, defending an improved version of it (Marcacci 2020). From the latter, he learns how to structure his arguments, abandoning presentations based on poetry and moving to more rigorous systems. ${ }^{7}$ However, it is also important to notice that the way Melissus' ideas are presented is, in some way, inspired by the naturalism of Ionic thinkers (Sedley 1999; Mansfeld 2016; Harriman 2019). Melissus has thus defended a particular type of monism (Palmer 2004) employing interesting arguments which, as already pointed out, will be presented in this paper through contemporary formal languages. ${ }^{8}$ The results we obtained by doing so show that ancient thought was already highly rigorous, and ideas were presented clearly. Moreover, employing contemporary formal languages helps in clarifying some difficult aspects of Melissus' arguments. In particular, we investigate the interplay between the properties of Melissus' Being, we highlight the role of a few implicit premises in Melissus' argument, and we formally show that Melissus' fallacies do not hinder the generally high quality of his reasoning. Specifically, we achieve our goals partially formalizing Melissus' thinking employing first order predicate logic with identity, a temporal order and general extensional mereology.

The paper proceeds as follows: in Sect. 2, Melissus' theses will be outlined, highlighting all the important aspects of his arguments; in Sect. 3, Melissus' arguments will be explicitly presented, revealing the central role of Monism in them; in Sect. 4, a contemporary semi-formal presentation of the arguments previously offered will be given; finally, in Sect. 5, conclusions will be drawn and future works are indicated.

\section{Melissus' theses}

There are only fragments of the work of Melissus Peri physeos he peri tou ontos. They are bequeathed by Simplicius (Commentary on Aristotle's Physics). All the following commentaries about Melissus' fragments are due to authors that write nearly 1000 years after Melissus and they do not add anything to Simplicius. However, those fragments are the only sources available and the work here presented will be based on them.

\footnotetext{
6 This does not mean that we endorse Simplicius's interpretation.

7 For a very good introduction to Melissus see Pulpito (2016) and Harriman (2019). The latter emphasizes the argumentative character of Melissus' fragments. But see Mansfeld (2016), who underlines the residual chiastic structure of Melissus' text, probably derived by a more ancient oral tradition.

${ }^{8}$ See also Loenen (1951, pp. 143-144), where the general logical structure of Melissus' thinking is presented, and single properties of the Being are emphasized, while their connections are stressed.
} 
From the few fragments of Melissus' works, it is possible to derive some general theses ${ }^{9}$ :

1. Permanence: Nothing begins, and nothing ends. ${ }^{10}$

2. Eternism: Eternity of all that is. ${ }^{11}$

3. Infinity: The Being is infinite in size.

4. Existence: There exists at least one Being. ${ }^{12}$

5. Monism: If there is at least one Being, then there is only one Being. ${ }^{13}$

6. Indestructibility: The Being can't be destroyed.

7. Homogeneity: The Being has no qualitative differences.

8. Isometry: The Being can't grow or shrink, neither generally nor in one of its parts.

9. Isomorphism: The Being can't swap its parts, nor can it modify, grow or shrink any of them.

10. Apathy: The Being does not suffer.

11. Fullness: There is no void.

12. Intangibility: The Being is not corporal.

13. Immutability: The Being does not change.

14. Determinateness: There are no differences in density.

15. Immobility: The Being can't change place.

16. Penetrability: Parts of Being can penetrate and go out.

\footnotetext{
9 Note that the labels describing the theses are not present in Melissus. For a comparison between our labels and Barnes' labels, see the "Appendix 1".

10 The thesis of Permanence includes the features of "not having a principle" and "not having an end". Melissus refers also to "being begotten", which can be considered internal to the thesis of Permanence. In our interpretation, we assume Simplicius' point of view, according to whom "coming about" is the opposite of "being eternal", so that we identify "coming about" and "having a principle". The interpretation seems to be confirmed by the passage (D) of the fragment D3 below. On this topic see also Barnes (1982, p. 185ff.).

Both "being begotten" and "having a principle" are more presented and repeated in Melissus' fragments then "not having an end", as many scholars noticed: according to the latter, the thesis "not having an end" is logically weaker and also more easily demonstrable than that of "coming about" and "having a principle" (Vitali 1973, pp. 173-174). On the contrary we consider them on a par, since Melissus introduces "having a principle" and "having an end" in a symmetric fashion (confirmed recently also by Bremond 2017, pp. 113-119; however, she draws on this assumption to show how Simplicius would have dissolved the doubt about Aristotle's fallacy, unlike us).

11 This shall not be confused with Eternalism, for which past, present and future are ontologically on the same level. About the role of the time and the relation between temporality and extra-temporality in Melissus' thought, see Drodzdek (2001) and Pulpito (2017).

12 Barnes $(1982,181)$ interprets Existence in a slightly different fashion: if we can think and talk about O, then $\mathrm{O}$ exists. Melissus is not so explicitly Russellian, so we prefer to assume that something exists (Palmer 2004).

13 Note that we bypass all problems of identity connected with Monism, investigated, for instance, by Merrill (1998, p. 376ff.), because we do not intend Existence in the Russellian fashion. See preceding footnote.
} 
There is a hot debate concerning which of these theses is peculiar to Melissus' thought, with respect to Parmenides. ${ }^{14}$ It seems that Infinity and Monism are original to Melissus, while the others can be found in previous works of Parmenides. ${ }^{15}$ The theses here presented can be found in various passages. ${ }^{16}$

Since theses (6), (7), (8) and (9) might be confused, some examples will be presented, showing what happens whenever such theses do not hold for an object. For this purpose, we must take "the time" as the fundamental reference. As we shall see later, the thesis of the "eternity of what is", is fundamental for Melissus. This can be seen, above all, in passages such as "it is eternal, unlimited, one, and entirely similar" (LM D10, DK B7).

With regards to temporality and eternity, theses (6), (7), (8) and (9) can be clarified considering what are their violations:

Violation of thesis (6), i.e., Indestructability

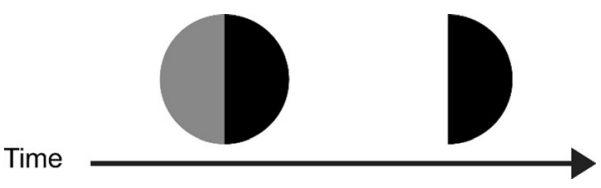

One of the two components of the Being have disappeared after some time. Violation of thesis (7), i.e., Homogeneity

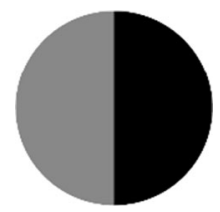

The Being has two parts with different properties. ${ }^{17}$

Violations of thesis (8), i.e., Isometry

\footnotetext{
14 On this see Pulpito (2016). We know that there are different interpretations of Melissus' philosophy, as, for instance, that of Loenen (1951), who distinguishes in Melissus two different entities: Being and Thought. If this point of view were correct, Melissus' monism would become a form of what Schaffer (2016) dubbed "priority monism", that is the thesis according to which all being is one in the sense that only one entity grounds all realities, that is Thought. Moreover, let us emphasize that Melissus' monism, as interpreted by Loenen-would be a form of priority monism different from that of Shaffer, since the basic entity would be abstract and not concrete.

15 DK: Diels and Kranz (1985) and LM: Laks and Most (2016).

${ }^{16}$ Here some specific references for each thesis: Permanence (fr. 7.3=LM D10), Eternism (fr. $2=$ LM D3, fr. 3=LM D4, fr. 7.1=LM D10), Infinity (fr. 3=LM D4, fr. 7.1=LM D10), Existence (fr. 1, fr. 2), Monism (fr. 5, fr. 6), Indestructibility (fr. 7.2), Homogeneity (fr. 7.1=LM D10), Isometry (fr. 7.2=LM D10), Isomorphism (fr. 7.3=LM D10, fr. 7.8=LM D11), Apathy (fr. 7.4=LM D10), Fullness (fr. 7.7=LM D10), Intangibility (fr. 9). Immobility (fr. 7.10), Indivisibility (fr. 8.1=LM D11, fr. 10=LM D9), Determinateness (fr. 7 = LM. D10), Immobility, (fr. 7, = LM D10), Penetrability, (fr. 7, = LM D10). "fr" refers to DK.

${ }^{17}$ Here we follow Merrill (1998, p. 375), who accepts $M X G$ 's interpretation.
} 

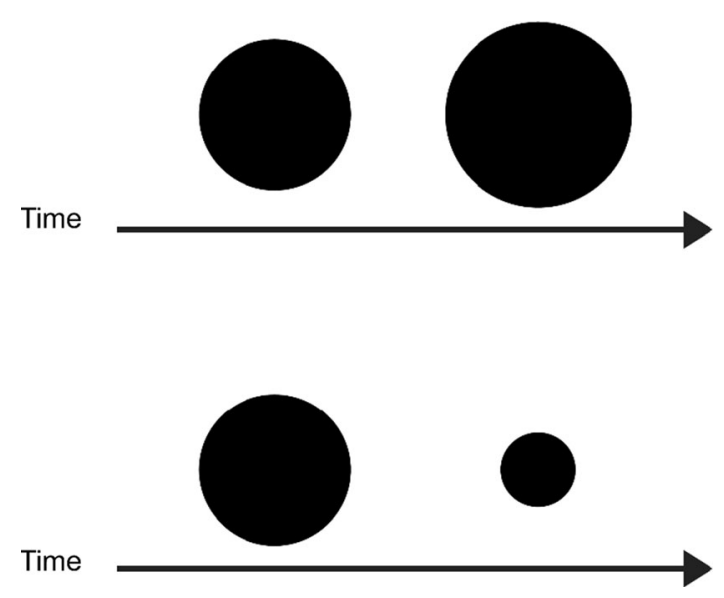

After some time, the Being grows or shrinks.

Time
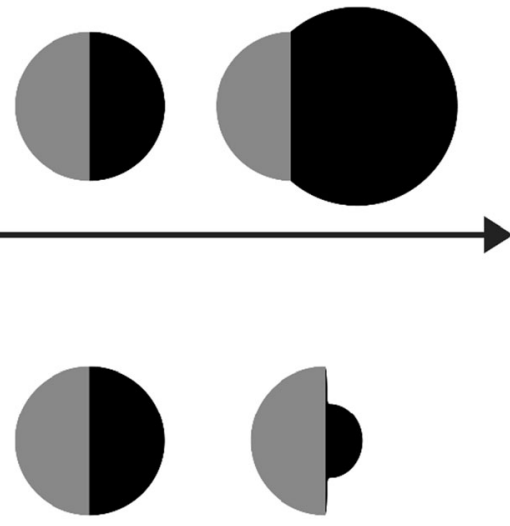

Time

After some time, one part of Being grows or shrinks.

Violation of thesis (9), i.e., Isomorphism

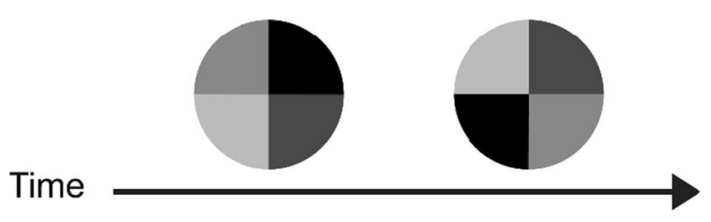

After some time, the Being swaps its parts. 
It is plausible to hold that thesis (6) (Indestructability) is a particular case of thesis (8) (Isometry), because if something can't shrink it can't a fortiori disappear. Even though obvious, the available fragments from Melissus do not contain such a claim.

We emphasize that in our interpretation Isometry and Homogeneity imply Isomorphism.

Note also that, in the available fragments, Melissus does not talk about qualitative change of the Being or one of its parts. However, such changes seem to naturally occur as special cases of the theses presented. A qualitative change of a part can be considered a violation of thesis (7) (Homogeneity), while a qualitative change of the whole Being can be considered a violation of thesis (1) (Permanence), since a whole Being that alters one of its global properties becomes another Being, thus something that begins to exist.

\section{Melissus' arguments}

The analysis presented in this paper is based on the translation of Laks and Most (2016). ${ }^{18}$ LM's translations will therefore be used as textual evidence for the sixteen theses introduced in the previous section. Moreover, the same translation will be employed to highlight the relations between the theses. ${ }^{19}$

Simplicius introduces the attributes of Being as eternal and in opposition to

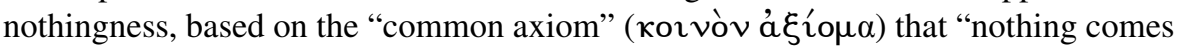
from what is not". Thus, the incipit of the fragment affirms the total absence of a beginning:

D2a (DK B1): (A) What was has always been and always will be. (B) For if it came to be, it is necessary that it was nothing before it came to be. ${ }^{20}$

Referring to the thesis 1-16, three of them (Existence, Eternism, Permanence ${ }^{21}$ ) are especially involved in the passage above, thus it follows that ${ }^{22}$ :

A. Existence $\Rightarrow$ Eternism. ${ }^{23}$

B. $\sim$ Permanence $\Rightarrow \sim$ Existence.

\footnotetext{
18 We use LM edition of the fragments because it considers all previous philological works (e.g., Curd 2011) and takes into account the most recent studies on pre-Socratics.

19 See the "Appendix 1" for a comparison between Barnes' and our analyses of Melissus' arguments.

${ }^{20}$ We neglect the last part of the fragment, since it has not a clear interpretation. However, it must be added that our notion of Permanence implies the impossibility of creatio ex nihilo as well. To this thesis Melissus refers in the last part of the fragment. According to Merrill (1998, p. 361ff), Melissus is the first to express this principle.

21 The thesis of Permanence includes the feature of 'coming about'.

22 Here arrows represent an informal notion of implication and tilde that of negation.

23 Indeed Barnes (1982, p. 181) deduces T2 and T3 from A. We substitute A with Existence and we identify $\mathrm{T} 2$ and $\mathrm{T} 3$.
} 
By contraposition ${ }^{24}$ directly by $\mathrm{B}$ :

Existence $\Rightarrow$ Permanence.

Given that implication (B) is employed to explain implication (A), it seems clear that Melissus assumes Existence as fundamental. Now we move to another fragment.

D3 (B2): (C) Since therefore it did not come about, but is, it always was and always will be, and has neither a beginning, nor an end, but is unlimited. (D) For if it came about, it would have a beginning (for it would have begun if it had come about at some time) and an end (for it would have come to an end if it had come about at some time). (E) But if it has neither begun nor come to an end, always was and always will be, then it has neither a beginning nor an end. (F) For it is impossible, for what is not entirely, to be forever.

Here 'unlimited' ('áreıрóv) in (C) should be interpreted temporally, since, after the term is introduced, Melissus only talks about the existence in time. ${ }^{25}$

\section{Permanence $\Rightarrow$ Eternism}

Aristotle (LM, R9) interprets the entire passage as based on the identification between "being begotten" ("coming about") and "having a principle". 26 This is what seems to happen in the passage (D) of the fragment.

\section{D. $\sim$ Permanence $\Rightarrow \sim$ Eternism}

According to Aristotle (Soph. E. 5 167b 13ff.), this identification brings Melissus to commit a fallacious reasoning (the fallacy of the consequent), that we can see in our reformulation, since evidently (C) does not follow from (D). ${ }^{27}$

Be it as it may, we have that from (C) and (D) it follows:

\section{E. Permanence $\Rightarrow$ Eternism $\Rightarrow$ Permanence}

Finally, the last passage seems to propose an implication, equivalent to the implication D:

$$
\text { F. } \sim \text { Permanence } \Rightarrow \sim \text { Eternism. }
$$

\footnotetext{
${ }^{24}$ It is not clear whether Melissus is able to manage the logical structure of implication. According to Aristotle he would commit a consequent fallacy (Soph. E. 5 167b 13ss.). Barnes (1982, pp. 154-155) agrees. We will come back to this in a moment.

25 Simplicius himself comments this point by involving the term "arche" (Paraphrasis of the fragment 2:

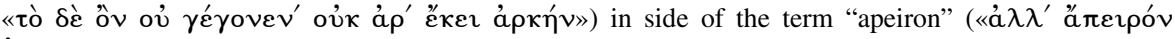
$\varepsilon \sigma \tau \imath \nu »)$, to make clear the reference to the temporal dimension. For a different interpretation see Sedley (1999): p. 126.

26 Exactly as we did.

27 Simplicius doubts whether the accusation of Aristotle is consistent or not (as Vitali also notes, Vitali 1973, 96; see also Reale 1970, 97 and Sedley 1999, 126-127). A careful analysis of Melissus's fragments (especially LM D3) should clarify whether the fallacy depends on Melissus himself or on an erroneous interpretation by Aristotle.
} 
Melissus goes on to derive the attribute of Infinity from that of Eternity.

D4 (B3): But just as it always is, in the same way it is necessary that it also always be unlimited in magnitude.

Which states that:

G. Eternism $\Rightarrow$ Infinity.

It can be argued that this claim is one of the most perilous in Melissus and one which will benefit a lot from the formal treatment given in this paper, because the relation between Infinity and the other features of what is becomes evident.

D5 (B4): Nothing that has a beginning and an end is either $(\mathrm{H})$ eternal or (I) unlimited.

Which states that:

H. $\sim$ Permanence $\Rightarrow \sim$ Eternism.

I. $\sim$ Permanence $\Rightarrow \sim$ Infinity.

What is unlimited in time is unlimited in size.

The thesis $(\mathrm{F})$ is repeated in $(\mathrm{H})$ : they are exactly the same. Besides, from (I), together with (D), (F), (C) and (H), it is possible to derive:

\section{J. Eternism $\Leftrightarrow$ Permanence $\Leftrightarrow$ Infinity.}

Melissus has now all the logical elements to obtain one of the most important theses for all Eleatism: there is only one Being.

D6 (B6): For (K) if it existed, it would have to be one. For, if (L) it were two, it could not be unlimited, but they would limit each other.

Which states that:

K. Existence $\Rightarrow$ Monism.

L. $\sim$ Monism $\Rightarrow \sim$ Infinity.

(L) is employed to explain (K), thus Infinity is assumed, as a postulate. However, as it has already been argued, Infinity can be derived directly from Permanence (which was already assumed).

We skip (D7) which is similar to (D6).

D8 (B9): If it were something that is, it must be one. But (M) if it is one, it must not have a body.

The first part of the fragment is equivalent to $(\mathrm{K})$, while the second states that:

M. Monism $\Rightarrow$ Intangibility. 
The concept of Intangibility in Melissus has attracted much attention, ${ }^{28}$ however, no further important remarks will be made on the notion. It is important to note, nonetheless, that LM highlights that in fragment D8 "intangibility" refers to the notion of "with no shape". Passing to the following fragment:

D9 (B10): (N) For if what is divided, [...] it moves. (O) But if it moved it would not exist.

We interpret the possibility of being divided as the negation of Monism. ${ }^{29}$ For Immutability, term which is not directly from the Melissean lexicon, we intend Isometry, Apathy and Homogeneity all together, as we will show below. Moreover, even if in (N) and (O) Melissus is using the verb "to move" ( $\llcorner\imath \varepsilon \varepsilon \omega)$, as in the successive argument (V), it is evident that he is not speaking of Immobility, but of Immutability. The latter is an internal change, whereas the former is a global displacement. Indeed, if the Being had internal differences - it would have divisible parts - then it could, in theory, be changed internally, that is it would be mutable. Thus, D9 (B10) states that:

$$
\begin{aligned}
& \text { N. } \sim \text { Monism } \Rightarrow \sim \text { Immutability } \\
& \text { O. } \sim \text { Immutability } \Rightarrow \sim \text { Existence. }
\end{aligned}
$$

Thus, it is possible to derive, by contraposition, Monism from Immutability. In fact, if something can be divided, then it can also move. However, Melissus argues, right after, that moving is impossible, since it would imply Non-Existence. The next fragment helps to understand what Melissus thinks about Immutability.

D10 (B7): (P) In this way therefore it is eternal, unlimited, one, and entirely similar, and it could not either be destroyed, nor increase in size, nor change its arrangement, nor suffer ether pain or distress. (Q) For if it underwent any of these affections, it would no longer be one. (R) For if it becomes different, it is necessary that what is not be similar, but that what was before be destroyed, and what is not come to be. If then the whole had become different by a single hair in the course of thousands of years, it would have been destroyed in the whole of this time.

(S) But neither is it possible that it changes its arrangement. For the arrangement that was before is not destroyed, and the one that is not does not come to be. But since nothing is added nor is destroyed nor becomes different, then how could any of the things that are change its arrangement? For only if it becomes something of a different sort, could it then change its arrangement. (T) Nor does it feel pain: for it could not feel pain as a whole. For a thing could not always feel pain, nor [i.e. when it feels pain] does it have the same capacity as what is healthy. Nor would it be similar, if it felt pain; for it would be because something left it or were added that it would feel pain, and then it would no longer be similar. What is healthy would not be able to feel pain

\footnotetext{
28 See, for example, Booth (1958) and Palmer (2003).

29 See footnote 37 .
} 
either: for what is healthy and what is would be destroyed, and what is not would come to be. And the same argument applies to distress and to pain.

(U) And there is not any void. For the void is nothing. But what is nothing could not exist. (V) Nor does it move. For it has nowhere it can recede to, but it is full; for if there were void, it would recede toward the void; but since the void does not exist, it has nowhere to recede to. And it could not be either dense or rarefied; for it is not possible that what is rarefied be full in the same way as the dense is, but the rarefied itself, must come to be more void then the dense. (W) The question whether it is full or not full must be decided in this way: if something goes out or penetrates into it, it is not full; but if nothing either goes out or penetrates into it, it is full. Hence it is necessary that it be full, if there is no void. Hence if it is full, it does not move.

Which states that:

P. Eternism $\wedge$ Infinity $\wedge$ Monism $\wedge$ Indestructability $\wedge$ Homogeneity $\wedge$ Isometry $\wedge$ Isomorphism $\wedge$ Apathy.

The first three properties of the Being were already derivable from previous fragments, while the latter five are introduced with this fragment. Given that Indestructability is a special case of Isometry, the former will not be considered from now on.

Q. ( Eternism $\vee \sim$ Infinity $\vee \sim$ Monism $\vee \sim$ Homogeneity $\vee \sim$ Isometry $\vee \sim$ Isomorphism $\vee \sim$ Apathy $) \Rightarrow \sim$ Monism.

That the first three elements of the disjunction imply the consequent is either trivial or was already known from previous fragments; all the other elements of the disjunction add further information. However, Melissus argues that (Q) follows from:

R. $\sim$ (Homogeneity $\wedge$ Isometry $\wedge$ Isomorphism $\wedge$ Apathy $) \Rightarrow \sim$ Permanence.

This element of the fragment explains why all modifications aren't possible. In fact, assuming (1) Permanence (as Melissus does), each one of those modifications would violate the assumption. It is known, moreover, that, following from ( $\mathrm{J})$, (K) and (L), if (1) Permanence is violated, then also (5) Monism is.

Then, we arrive to:

S. Isomorphism $\Leftrightarrow$ (Homogeneity $\wedge$ Isometry $)$.

This is in perfect agreement with our exemplification in Sect. 2.

From the fragment it is also possible to derive:

T. $\sim$ Apathy $\Rightarrow \sim$ Permanence.

Moreover, let us emphasize that thesis (R) suggests that:

Homogeneity $\wedge$ Isometry $\wedge$ Isomorphism $\wedge$ Apathy $\equiv$ Immutability. 
It is reasonable to hypothesize that Melissus endorses Apathy in order to avoid anthropomorphism (Harriman, 2019, 169), therefore, since it is not a strictly metaphysical feature, here we ignored it. The consequence of our negligence is that in our framework Immutability and Isomorphism are synonymous. Despite this, keep in mind that:

\section{Isomorphism $\wedge$ Apathy $\Leftrightarrow$ Immutability}

It follows that:

\section{Isometry $\wedge$ Homogeneity $\Leftrightarrow$ Immutability}

To sum up, D10 helps us to understand better Melissus' notion of Immutability.

It will soon be shown that for Melissus void does not exist. (9) Isomorphism prohibits every kind of change, except for the possible mutations of the whole Being, which are prohibited by the impossibility of void.

The last passage seems to indicate another assumption made by Melissus, where an implicit premise seems to be that Void implies Non-Existence. Thus:

$$
\text { U. } \sim \text { Fullness } \Rightarrow \sim \text { Existence. }
$$

Note that Melissus refers here to movement in the sense of displacement, that is (16) Immobility. We have:

\section{Fullness $\Rightarrow$ (Immobility $\wedge$ Determinateness $)$.}

It is interesting to emphasize that Melissus in (W) does another fallacy of affirming the consequent. Indeed, the text can be so formalized:

\section{W. Penetrability $\Rightarrow \sim$ Fullness, therefore $\sim$ Penetrability $\Rightarrow$ Fullness}

Note that, reading the text, the fallacy is not so trivially evident. This means that Melissus was only partially aware of how the conditional works. We will not come back to these theses.

Now we move to the following fragment.

D11 (B8): The greatest proof that it is only one is this argument, but these following ones are also proofs. For if many things existed, they would have to be exactly like what I myself say that the one is. For if earth exists and water, air, iron, gold, fire, the living and dead, black and white, and the other things of which humans say that they are true, if then all these things exist, and we see and hear correctly, then it is necessary that each thing of this sort be as it first seemed to us, and that it does not change or become different, but that each one always be as it is. But as it is, we say that we see, hear, and understand correctly, but it seems to us that what is hot becomes cold and what is cold hot, what is hard soft and what is soft hard, that what is living dies and that it comes to be out of what is not living, and that all these things become different, and that what was and what is now are not at all similar, but that iron, although it is hard, is rubbed away by the finger and at the same time 
flows, and likewise gold, stone, end everything else that seems to be resistant, and that earth and stone come to be out of water, so that the result is that we neither see nor know the things that are. Hence these [i.e. statements] do not agree with one another. For although we say that they are many, eternal, that they possess forms and force, it seems to us that they all become different and change out of what is seen each time. Hence it is clear that we do not see correctly, and that it is not correctly that these things seem to us to be many. For they would not change if they were true, but they would be just as each one seemed to us to be. For there is nothing stronger than what truly is; but if it changed, then what is would be destroyed, while what is not would come to be. In this way, therefore, if many things existed, they would have to be exactly like the one.

As argued by Melissus at the start of the fragment, this last passage is extremely important. It starts by assuming (1) Permanence - as it is highlighted in the text by the italic (added by us) — and it then argues that multitudes of things are illusory. The argument proceeds briefly as follows:

(a) Many things are perceived.

(b) It is perceived that things change.

(c) Assume Permanence.

(d) Thus, the perception that things change is illusory.

(e) Thus, also the perception of the existence of many different things is illusory.

We won't dwell much on this epistemological argument. We emphasize only that it is based on an ontological thesis, that is Permanence. The truth of Permanence implies the deceitfulness of perception. Then, even the perception of multiplicity will be illusory.

Summing up, from Existence it is possible to derive Eternism, which is equivalent to Permanence. From Existence it is possible to derive Fullness. This point is controversial and many philosophers coming after Melissus will criticize this issue (e.g., Aristotle (LM, R12)). In what follows no more attention will be paid to this controversial question. Continuing, from Existence it is possible to derive Monism. However, this point follows, strictly, from the implication between Infinity and Monism. Moreover, Monism follows also from Permanence. Yet, the argument which supports this claim is not purely metaphysical, thus it is partially ignored in the reconstruction presented in this paper. Note, however, that the argument for (U) is partially flawed. The conclusion (e) doesn't follow necessarily from conclusion (d): the fact that a certain type of perception (that of change) is illusory doesn't necessarily imply that all perceptions are illusory and, in particular, that perceiving multiple objects is. Finally, from those fragments it is possible to derive that Immobility implies Indivisibility and that Permanence implies Immobility.

See "Appendix 2" for a schematic representation of the main part of the arguments presented above. From "Appendix 2" it is easy to recognize the central role (2) Eternism plays in Melissus' arguments. ${ }^{30}$ (5) Monism, from a logical point-

${ }^{30}$ Immediately after Existence, which is the main general presupposition. 
of-view, is subordinate to the other positions. Finally, (2) Eternism and (1) Permanence are equivalent, thus also the latter plays a central role in all arguments.

Before going to the next section, it might prove useful to confront the analysis provided here with the one of two authors closer to Melissus' times: Aristotle and Simplicius.

Starting with Aristotle, in D19 he highlights that: "He says that if something is, it is eternal, if it is true that it is not possible that anything can come to be out of nothing." Thus, (4) Existence implies (2) Eternism, based on (1) Permanence. Not long after, he argues "But if it is eternal, it is unlimited", thus (2) Eternism implies (3) Infinity. "But Being all and unlimited it is one", thus (3) Infinity implies (5) Monism. Finally, "But if it is eternal, immense and everywhere similar, the One is immobile". That is Aristotle emphasizes Immobility.

Moving to Simplicius, according to D20: "But if something is, either it comes to be, or it always is. But if it comes to be, then that is either out of something that is, or out of something that is not. But it is not possible for anything [...] to come about either to come about out of what is not nor out of what is", again (4) Existence implies (2) Eternism, based on (1) Permanence. Following, "What has neither a beginning nor an end turns out to be unlimited", from (2) Eternism it can be derived (3) Infinity. Then, "But if it is unlimited, it is one.", from (3) Infinity to (5) Monism. Finally, "But again, if it is one it is also immobile.", from (5) Monism to (13) Immobility.

Therefore, this paper presents an analysis of Melissus in line with the ones provided by both Aristotle and Simplicius. This should increase the plausibility of the interpretation given here of Melissus' thought. ${ }^{31}$

\section{Formalization}

In this section, Melissus theses and arguments will be structured and presented employing contemporary semi-formal techniques. Note that we will not provide a formal system, but we will simply use a formalization to further clarify Melissus' philosophical system. The first choice is thus that of a suitable formal framework that can help in achieving the desired results.

The choices made in this paper are the following:

I. The main formal framework will be that of First-Order Logic with identity. This choice is driven by considerations of expressivity. It is thought that propositional logic wouldn't be enough to represent Melissus' arguments and secondorder logic would be too expressive, since in Melissus quantification on properties seem to never occur. Explicit use of modalities is never made, thus there is no need to employ modal logics, even though it is plausible to hold that Melissus' arguments always have a de dicto modal force (Palmer 2004).

\footnotetext{
31 Here a comparison with the very recent reconstruction by Harriman (2019, appendix 3) is in order. Harriman begins as well with Existence, from which Eternism is derived. From Eternism, Permanence and Infinity are deduced. Then, from Infinity derives Monism. Therefore, Harriman's schema, in its main part, is quite similar to ours. In spite of this, there are few differences in the remaining less important part of the argumentation.
} 
II. According to temporal considerations, Theory $B^{32}$ of time will be employed. This choice is driven by the feeling that time, as described by Theory B, is what Melissus had in mind; in fact, Melissus never makes references to past, present or future, but only talks about instants in the temporal series.

III. No notion of space will be employed. Simplicius is clear in saying that Melissus never thought of "size" as a spatial notion and thus space is not necessary to formalize his arguments (Physica, 109, 32). ${ }^{33}$

IV. We assume that the mereological structure of Melissus' Being is the so-called "General Extensional Mereology". On this, more will be said in the following part of the paper. Instants of time are parts of Melissus' Being.

In the formal framework presented, some predicates will play a special role. In particular: the unary property $T u$, whose meaning is " $u$ is a time instant" 34 ; the binary predicate $B x y$, whose meaning is " $x$ is at time $y$ "; a binary predicate PPxy, whose meaning is " $x$ is a proper part of $y$ "; a binary predicate $u \prec v$, whose meaning is " $u$ temporally comes before $v$ ". Furthermore, not all parts of being are $T$. Formally, $P P$ is a partial order, thus antisymmetric and transitive, while $\prec$ is a dense linear order, thus irreflexive, antisymmetric, total and dense. "Bxy" is such that $T y$ must hold, and it is reflexive, that is for each $x$ such that $T x$ then $B x x$; furthermore, if $B x y$ then Pyx. Moreover, $\prec$ has no upper and lower bound, thus it defines infinite orders in both directions, i.e., the Property of Infinity of Time holds:

Ax1. $T u \rightarrow \exists v \exists z(T v \wedge T z \wedge v \prec u \wedge u \prec z){ }^{35}$

Let us emphasize that $\prec$ is irreflexive, therefore $v$ and $z$ must be different from $u$. Even though the predicate $\prec$ is important, it will seldom be employed, since Melissus' arguments are almost symmetrical from the temporal point-of view. Specifically, all that is true for the concept of "before" also applies to "after". Notwithstanding, a linear temporal order is presupposed.

Starting from the predicates introduced above, other predicates can be derived. In particular, to facilitate future arguments, the notion of part is introduced:

$$
P x y={ }_{d f} P P x y \vee x=y .
$$

This new predicate is instantaneous, i.e., the principle of mereosynchronicity holds for the predicate.

Ax2. $\quad((P x y \wedge T u \wedge B y u) \rightarrow B x u) \wedge((P x y \wedge T u \wedge B x u) \rightarrow B y u)$.

\footnotetext{
32 Theory $B$ of time claims that time is an ordinate series of instants and that the passage from past, to present, to future is only illusory.

33 For different interpretations, see Vitali (1973: p. 297ss).

34 From an ontological point of view, it would be better to leave time instant out of the picture, since they are infinitesimal parts, thus working only with time lapses. However, time instants help in facilitating the presentation and, for this reason, they are explicitly introduced in the paper. Indeed, as we will see in a moment, they will have no null measure.

35 From now on, all free variables occurring in formulas should be thought of as being closed under universal quantification.
} 
Another predicate definable from the ones introduced earlier is that of overlapping, Oxy:

$$
O x y={ }_{d f} \exists z(P z x \wedge P z y)
$$

A new axiom can now be introduced:

Ax3. $\sim P x y \rightarrow \exists z(P z y \wedge \sim O x z)$.

Axiom 3 is commonly called the Principle of Strong Supplementation in the mereological literature. Another composition principle that will be assumed is that of Unrestricted Fusion:

Ax4. $\exists w \varphi(w) \rightarrow \exists z \forall w(O z w \leftrightarrow \exists v(\varphi(v) \wedge O v w))$.

Given the Axioms 2-4, it holds that the predicate $P$ defines a notion of part typical of General Extensional Mereology (GEM). ${ }^{36}$

Ax4. give us the possibility to define a very general notion of mereological sum:

$$
x \oplus y=z={ }_{d f} \forall w(O z w \leftrightarrow(O w x \vee O w y))
$$

Melissus' Being can have parts, ${ }^{37}$ but those parts are necessarily homogeneous and indivisible. Moreover, those parts can't be infinitesimal. This point requires clarification. Even though Melissus' Being is not a spatial entity, it still has size, thus a measure of what it is is necessary. This can be done by introducing a measuring function $M: x \rightarrow \mathbb{Q}^{+\infty}$. The arguments of this function are the parts of being (instant comprehended) and the values are positive rational numbers, to which infinity is added. We do not define formally ' $M$ ', but Melissus' Being as regimented by General Extensional Mereology seems adequate to host a sort of "pseudomeasure" respecting these rules:

1.

$$
M(x) \neq 0
$$

2.

$$
M(x \oplus y)=M(x)+M(y)
$$

3.

$$
T u \wedge T v \rightarrow M(u)=M(v)
$$

For the function $M$, it is also defined the pseudo-measure of the countable mereological sum of things as the arithmetical sum of the pseudo-measure of the things. This is allowed by the unrestricted fusion, Ax4.

\footnotetext{
36 See Varzi (2016) for a complete discussion.

37 It is usual to differentiate between distinguishable and separable parts in analytic metaphysics. In our case we refer to the concept of distinguishable parts, and not of separable parts. In fact, the last part of the fragment B9 in DK ('if it possessed thickness, it would have parts, and would no longer be one') seems to exclude explicitly separable parts in the Being. LM's translation of the fragment B9 eliminate this passage entirely.
} 
Thus, everything in Melissus' being has positive either rational or infinite pseudo-measure. Consequently, nothing can be infinitesimal. ${ }^{38}$

It is now possible to formalize Melissus' theses. Existence can be formulated through $B$ :

\section{Existence: $\exists x \exists u B x u$}

\section{Now we formalize Eternism:}

Eternism: $(T u \wedge T v \wedge u \neq v \wedge B x u) \rightarrow B x v$.

This principle affirms that if something exists at a given instant, then it exists at each instant. Compare this principle with the principle of Permanence:

Permanence: $\sim(T u \wedge T v \wedge u \neq v \wedge B x u \wedge \sim B x v)$.

This principle affirms that it is not true that something is at an instant and then it stops being at another. It is easy to show that the two principles are equivalent, as required by the analysis provided in previous sections. On the other hand, there is a difference between our formal reconstruction and Melissus' metaphysics. Indeed, Melissus derives Permanence form Existence, while we have assumed either Permanence, or Eternism. Nonetheless, if one wants to be nearer to the meaning of Melissus' text, it would be better to consider either Permanence or Eternism not as a metaphysical axiom, but as an axiom defining the ontological meaning of predicate $B$. If Permanence defines $B$ 's sense, then from Existence, which is bounded to a certain instant, one can derive Existence at another instant, that is Eternism.

According to Melissus time is not a parameter, as argued in classical physics, but a real entity. As said above, time is infinite both in the past and in the future. Moreover, time is not generated, since there is no higher-order time where time itself and time instants belong. It therefore holds that:

Reality of Time: $T u \rightarrow(B x u \rightarrow P P u x)$.

This principle affirms that if $u$ is a time instant, then $u$ is a proper part of an object belonging to that time instant $u$. From Eternism, Reality of Time and the Infinity of Time, it is possible to deduce the infinity of the pseudo-measure of what is:

$$
\text { Infinity: } M(x)=\infty \text {. }
$$

The proof of Infinity is per absurdo. Let us assume:

$$
M(x)=n \text { with } n \in \mathbb{Q}^{+}
$$

From Existence and the peculiarities of $B$ we deduce that there is at least one instant of time $u$. Then, from Infinity of time we derive that there is at least another different instant of time $v$. From Eternity we deduce that $x$ exists also at $v$. From the

\footnotetext{
38 Note that the consistency of this formal system is yet to be proven. This proof won't be given in this paper, but it will be the target of a future paper.
} 
peculiarity of $B$, we derive that $v$ is a part of $x$. Now, without losing generality, let us assume that:

$$
M(u)=M(v)=l \text { with } l \in \mathbb{Q}^{+}
$$

It is easy to deduce that $u \oplus v$ is a part of $x$. But as a consequence of (1)-(3) $M(u \oplus v)=2 l$ and $M(x)>2 l$.

Now repeat this argument $n / l+1$ times and you reach the conclusion that $M(x)>n$ against the hypothesis.

The fact that Melissus had clear in mind a similar argument can be seen in the following passage by Aristotle (LM, D19, 2): "But if it is eternal, it is unlimited, because it does not have a beginning starting from which it could come to be, nor an end toward which it would ever be terminated.". This fragment shows that time is infinite and that Being is infinite in size. Thus, the arguments in fragment D4 is explained and the Infinity of Time is finally connected to the infinity of size.

Now we pass to investigate Monism:

$$
\text { Monism: } \sim T x \rightarrow \forall y(P y x)
$$

The antecedent of Monism asserts that $x$ is not an instant. The consequent that all is a part of $x$.

Consider again the fragment where Melissus argues from Infinity to Monism, i.e., D6:

"For if it existed, it would have to be one. For, if it were two, it could not be unlimited, but they would limit each other."

An implicit premise in such argument is the fact that there can't exist two infinite entities at the same time. ${ }^{39}$ It is thus possible to make explicit another premise that is implicit in Melissus:

Monoinfinity: $(M(x)=\infty \wedge M(y)=\infty) \rightarrow x=y$.

Informal proof of Monism from Infinity and Monoinfinity. From Existence and Infinity of time we arrive at the conclusion that there are other instants of time. But the very definition of $B$ imposes that they are parts of $x$. So, all instant of times are parts of $x$. Moreover, the predicate $P$ is reflexive, then $P x x$ holds. Hence all existent entities are parts of $x$. But Existence states that there is at least one $x$. Therefore, there could be a second entity $y$, which is not part of $x$. It is easy to show that $M(y)=\infty$, following a proof similar to the preceding one. Now, from Monoinfinity, one can deduce that $x=y$. Therefore Pyx. Thus, we conclude that each entity is part of $x$.

\footnotetext{
39 Indeed, this derivation is one of the weakest in Melissus' argumentation. In a certain sense, adding Monoinfinity, we are begging the question of deriving Monism from Infinity. See on this Mansfeld (2016, p. 80). But, one can reformulate this part in a different fashion as well, following Merrill (1998, p. $373 \mathrm{ff}$.). In this perspective, to be infinite does not mean only to have infinite pseudo-measure, but do not have limits in general. From this different definition of Infinity, it is possible to derive directly Monism, but it is not clear how to formalize this different notion of Infinity.
} 
We can now investigate the other properties of Melissus' being. Indicating the possible properties of objects with the unary predicates $Q_{1} \ldots Q_{n}$ and assuming $i \neq j^{40}$ :

Homogeneity: $\sim\left(P P x y \wedge P P z y \wedge x \neq z \wedge Q_{i} x \wedge Q_{j} z\right)$.

This principle affirms that nothing can exist which has two proper parts with different properties. Homogeneity follows from Permanence only if it is presupposed that the principle of Eterogenesis holds, assuming $i \neq j$ :

Eterogenesis:

$\left(P P x y \wedge P P z y \wedge x \neq z \wedge Q_{i} x \wedge Q_{j} z\right) \rightarrow \exists u \exists v(T u \wedge T v \wedge u \prec v \wedge \sim B z u \wedge B z v)$.

This principle affirms that if there is not homogeneity between two proper parts of an object, then those two proper parts have been generated in different moments. Let us emphasize that the antecedent of Eterogenesis is equivalent to not Homogeneity, and the consequent of Eterogenesis is stronger than the negation of Permanence.

We go on with:

$$
\text { Isometry: } \sim(T u \wedge T v \wedge u \neq v \wedge P P x y \wedge((B x u \wedge \sim B y u) \vee(\sim B x u \wedge B y v))) .
$$

This principle affirms that nothing can gain or lose a proper part. Isometry follows directly from PermanencelEternism. Isomorphism, which can be represented as the logical conjunction of Isometry and Homogeneity, can be derived from Permanence with the help of Eterogenesis. It follows that from Permanence we also arrive to Immutability, since Immutability and Isomorphism are equivalent modulo Apathy, which we have neglected (as we previously stated).

Going ahead, we find that Melissus' definition of Fullness seems equivalent to Existence, since void is contradictory (Volpi (2017)). This means that it is possible to derive Fullness from Existence.

Note that Melissus deduces also Immutability from Existence. ${ }^{41}$ We have seen that Immutability is a consequence of Permanence, and that Permanence is, according to Melissus, an intrinsic part of the meaning of Existence. Therefore, in our formalism is quite clear as Immutability and Existence are connected. Indeed, in (O) Melissus states that Immutability derives from Existence. To be more precise, in (O) Melissus speaks of "movement", but from the context it is clear that he is referring to what we have dubbed "Immutability". If Immutability is equivalent to Isomorphism, ${ }^{42}$ and Isomorphism is derivable from Permanence, and Permanence is strictly connected with Existence, it becomes clear how Existence and Immutability can stay together in Melissus' text (O).

We neglect the notion of Immobility, Intangibility and Determinateness, which could be the topic of further research.

\footnotetext{
40 See fragment D20.

41 (O) in Melissus' fragments.

42 Neglecting Apathy.
} 
This concludes our semi-formal reconstruction of Melissus' main arguments.

\section{Conclusion}

It has been shown that Melissus' work was logically rigorous, up to the point of allowing a partial formalization of it employing First-Order Predicate Logic with identity, a temporal order and general extensional mereology.

The approach here presented helped in clarifying many points in Melissus' arguments:

1. The relation between Homogeneity and Alteration has been made explicit. Melissus only talks about the former concept, insofar as Homogeneity excludes Alteration. Moreover, it was made clear that Indestructability is a direct consequence of Isometry.

2. It has been made evident why Melissus never talked about movement. Since Melissus rejects the existence of void, every movement would be equivalent to a rearrangement of the parts of the Being.

3. Permanence and Eternism have been equated, thus avoiding the fallacy that Aristotle's attributes to Melissus. Thus, Melissus' arguments become clearer and "sound".

4. Employing a mathematical concept of pseudo-measure, it has become clear how Melissus probably understood the infinity of Being in a non-spatial manner, as also noted in Simplicius D20.

5. The implicit assumption of the Reality of Time, needed to logically move from Eternism to Infinity in Melissus, has been made explicit.

6. The implicit assumption of the existence of a unique object infinite (what has been labelled Monoinfinity), needed to logically move from Infinity to Monism, has been made explicit.

7. The implicit assumption of the principle of differentiated temporal genesis of inhomogeneous parts (what has been labelled Eterogenesis), needed to logically move from Permanence to Homogeneity, has been made explicit.

8. The concept of Immutability introduced in fragment D9 has been reconnected formally to the analysis of fragment D10.

9. We have found another consequent fallacy.

This simple formalization helps in clarifying how Melissus was working in defining a highly abstract notion of Being, similar in spirit with the one ancient mathematicians were employing in the same period. Indeed, mathematicians elaborate explicitly their entities without relying on results and considerations related to perception. ${ }^{43}$

Concerning future works, the notions of Apathy, Immobility, Fullness and Intangibility must still be thoroughly analysed. Moreover, the three concepts introduced in this paper (i.e., Reality of Time, Monoinfinity and Eterogenesis) shall

\footnotetext{
${ }^{43}$ See Marcacci (2012) for a reflection on the link between Eleatism and the birth of Greek mathematics.
} 
be studied more profoundly with respect to other fragments and testimonies from Melissus' times.

Concluding, this paper helps in rehabilitating Melissus' works, following the path of Vitali (1973), who suggested that Melissus employed methodologies typical of contemporary analytic philosophy.

Acknowledgements Open access funding provided by Università degli Studi di Urbino Carlo Bo within the CRUI-CARE Agreement. Funding was provided by 2017ZNWW7F_004.

Open Access This article is licensed under a Creative Commons Attribution 4.0 International License, which permits use, sharing, adaptation, distribution and reproduction in any medium or format, as long as you give appropriate credit to the original author(s) and the source, provide a link to the Creative Commons licence, and indicate if changes were made. The images or other third party material in this article are included in the article's Creative Commons licence, unless indicated otherwise in a credit line to the material. If material is not included in the article's Creative Commons licence and your intended use is not permitted by statutory regulation or exceeds the permitted use, you will need to obtain permission directly from the copyright holder. To view a copy of this licence, visit http:// creativecommons.org/licenses/by/4.0/.

\section{Appendix 1}

\begin{tabular}{|c|c|c|}
\hline Barnes & Our paper & Questions \\
\hline $\begin{array}{l}\text { A (=axiom): } \mathrm{O} \\
\text { exist }\end{array}$ & Existence & \\
\hline $\begin{array}{l}\mathrm{T} 1: \mathrm{O} \text { is } \\
\text { ingenerated }\end{array}$ & $\begin{array}{l}\text { Permanence (nothing } \\
\text { begins, nothing ends) }\end{array}$ & \\
\hline $\mathrm{T} 2: \mathrm{O}$ is eternal & Eternism & As we argued in footnote 7 , we identify these two theses. \\
\hline $\begin{array}{l}\text { T3: } \mathrm{O} \text { is } \\
\text { temporally } \\
\text { unlimited }\end{array}$ & Eternism & \\
\hline $\begin{array}{l}\text { T4: } \mathrm{O} \text { is spatially } \\
\text { unlimited }\end{array}$ & Infinity & \\
\hline $\mathrm{T} 5: \mathrm{O}$ is unique & Monism & \\
\hline $\begin{array}{l}\text { T6: } \mathrm{O} \text { is } \\
\text { homogeneous }\end{array}$ & Homogeneity & \\
\hline $\begin{array}{l}\text { T7: O does not } \\
\text { alter }\end{array}$ & Isomorphism & \\
\hline $\begin{array}{l}\text { T8: } \mathrm{O} \text { is not } \\
\text { destroyed }\end{array}$ & Indestructability & \\
\hline $\begin{array}{l}\text { T9: O does not } \\
\text { grow }\end{array}$ & Isometry & \\
\hline $\begin{array}{l}\mathrm{T} 10: \mathrm{O} \text { is not } \\
\text { rearranged }\end{array}$ & Isomorphism & \\
\hline
\end{tabular}




\begin{tabular}{|c|c|c|}
\hline Barnes & Our paper & Questions \\
\hline $\begin{array}{l}\text { T11: O does not } \\
\text { suffer pain }\end{array}$ & Apathy & $\begin{array}{l}\text { Again, we identified the two theses, because here other } \\
\text { metaphysical problems are involved. See Barnes (1982, }\end{array}$ \\
\hline $\begin{array}{l}\text { T12: O does not } \\
\text { suffer anguish }\end{array}$ & Apathy & pp. 216-217) \\
\hline $\begin{array}{l}\text { T13: O is not } \\
\text { empty }\end{array}$ & Fullness & $\begin{array}{l}\text { We unified these two theses, but see Barnes (1982, } \\
\text { pp. 217-222) }\end{array}$ \\
\hline T14: $\mathrm{O}$ is full & Fullness & \\
\hline $\begin{array}{l}\text { T15: O does not } \\
\text { move }\end{array}$ & Immobility & \\
\hline (4) p. 227 & Intangibility & \\
\hline $\begin{array}{l}\text { T16. O is not } \\
\text { dense or rare }\end{array}$ & Determinateness & \\
\hline $\begin{array}{l}\text { T17: } \mathrm{O} \text { is not } \\
\text { divided up }\end{array}$ & Non-Monism & \\
\hline
\end{tabular}

\section{Appendix 2}

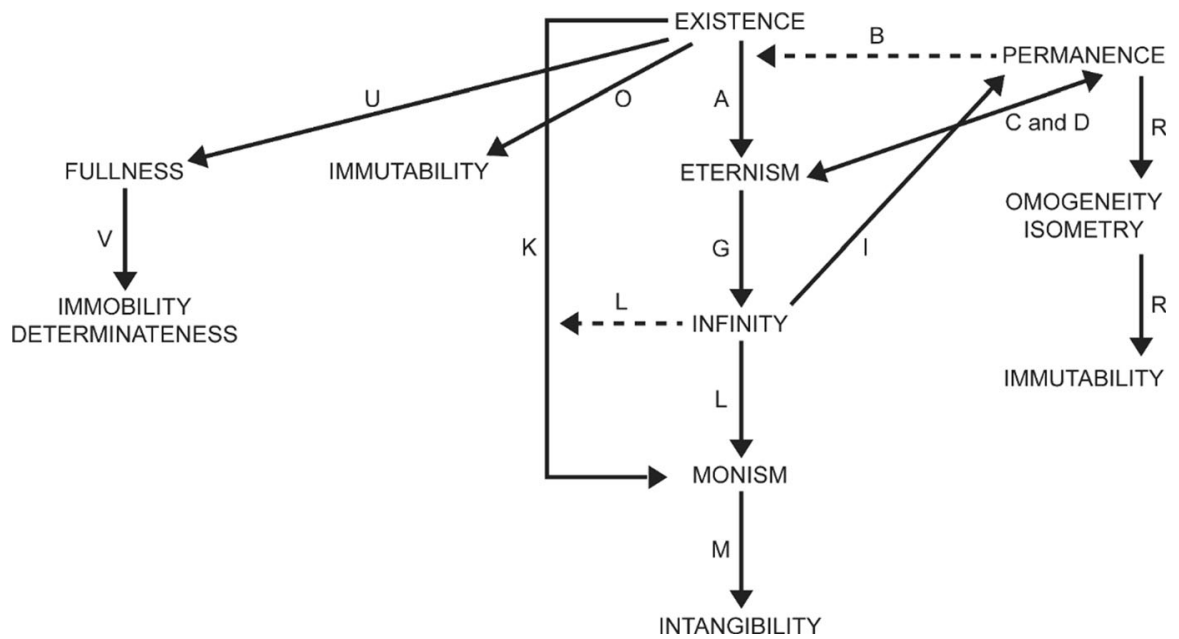

The continuous arrows indicate a derivation in Melissus' text. The capital letters refer to the step in Melissus' fragments. Dashed arrows refer to the job done by a thesis in a deduction 


\section{References}

Barnes J (1982) The presocratic philosophers. Routledge, London

Booth NB (1958) Did Melissus believes in incorporeal being? Am J Philol 79:61-65

Bremond M (2017) Lectures de Mélissos: édition, traduction et interprétation des témoignages sur Mélissos de Samos. De Gruyter, Berlin

Chisholm R (1976) Person and object: a metaphysical study. Open Court, Chicago

Curd P (2011) A presocratic reader. Hackett, Indianapolis

Diels H, Kranz W (1985) Die Fragmente der Vorsokratiker. Weidmann, Zurich-Hildesheim

Drozdek A (2001) Eleatic being: finite or infinite? Hermes 129:306-313

Harriman B (2019) Melissus and Eleatic Monism. Cambridge University Press, Cambridge

Hussey E (1997) Pythagoreans and Eleatics. In: Taylor CWW (ed) The Routledge history of philosophy, vol I. Routledge, London, pp 117-160

Ladyman J, Ross D (2007) Every thing must go. Metaphysics naturalized. Oxford University Press, Oxford

Laks A, Most GW (2016) Early Greek philosophy, vol 2. Harvard University Press, Cambridge

Lewis DK (1986) On the plurality of worlds. Wiley-Blackwell, Oxford

Loenen JHMM (1951) Parmenides, Melissus, Gorgias. Royal VanGorcum Ltd, Assen

Mansfeld J (2016) Melissus between Miletus and Elea. In: Mansfeld J et al (eds) Eleatica 5. Melissus between Miletus and Elea. Akademia Verlag, Sankt-Augustin, pp 71-112

Marcacci F (2012) Alle origini dell'assiomatica: gli Eleati, Aristotele, Euclide. Aracne, Rome

Marcacci F (2020) Argumentation and counterfactualreasoning in Parmenides and Melissus. Archai 30 (3):e03004. https://doi.org/10.14195/1984-249X_30_4)

Merrill BL (1998) Melissus of Samos. The University of Texas at Austin, PhD thesis

Palmer J (2003) On the alleged incorporeality of what is in Melissus. Anc Philos 23:1-10

Palmer J (2004) Melissus and Parmenides. Oxf Stud Anc Philos 26:19-54

Pulpito M (2016) Lo Straniero di Samo. Introduzione. In: Mansfeld J et al (eds) Eleatica 5. Melissus between Miletus and Elea. Academia Verlag, Sankt Augustin, pp 9-67

Pulpito M (2017) Melisso, il tempo e l'eterno. Peitho 1(8):107-121

Reale G (1970) Melisso. Testimonianze e frammenti. Nuova Italia, Firenze

Schaffer J (2016) Monism. In: Zalta EN (ed) The stanford encyclopedia of philosophy. https://plato. stanford.edu/archives/win2016/entries/monism/

Sedley D (1999) Parmenides and Melissus. In: Long AA (ed) The Cambridge companion to early Greek philosophy. Cambridge University Press, Cambridge, pp 113-133

Simons P (1987) Parts: a study in ontology. Oxford University Press, Oxford

Varzi A (2016) Mereology. In: Zalta EN (ed) The stanford encyclopedia of philosophy. https://plato. stanford.edu/archives/win2016/entries/mereology/

Vitali R (1973) Melisso di Samo sul mondo o sull'essere. Argalia, Urbino

Volpi E (2017) Melisso e il problema del vuoto: apologia e/o fraintendimento del monismo parmenideo. Peitho 1(8):91-106

Publisher's Note Springer Nature remains neutral with regard to jurisdictional claims in published maps and institutional affiliations. 